\title{
A Survey Study of Adoption of Mobile Payment in the U.S Market
}

\author{
Tingya Su \\ Portledge School \\ 355 Duck Pond Road, Locust Valley, NY 11560 \\ Qiping Zhang \\ Long Island University \\ 720 Northern Blvd, Greenvale, NY 11548
}

\begin{abstract}
Mobile payment obtained extensive attention in recent decades as a new means of commerce with various advantages. This paper aims to empirically investigate key adoption determinants that contribute to the relative slow uptake of mobile payment service in the U.S. market. The study aims to examine the key facilitators and hindrances in the mobile payment adoption process from the consumer perspective. We also take the varied demographic condition into consideration, that serves as the moderating factors in the adoption process of mobile payment, A survey is developed to understand people's intention and self-reported usage of mobile payment based on previous literature. The survey includes demographic information (such as age, gender, income, and education), and six constructs - performance expectancy, effort expectancy, social influence, facilitating condition, perceived risk, and individual innovativeness. All six constructs except effort expectancy showed significant direct effect to behavior intention.
\end{abstract}

Keywords: technology adoption, mobile payment, mobile commerce, influencing factors

\section{Introduction}

\subsection{Background}

Over the past few decades, mobile phones have been transformed from basic communication tools to multi-functional devices, equipped with functionality which far exceeds the needs of telephony. The United States has a high rate of smart phone ownership and an increasing level of Smartphone dependency. This paper focuses on a more recent innovation--mobile payment services.

M-payment refers to payments for goods, services, and bills made through mobile devices using wireless and other communication technologies (Dahlberg, Mallat, Ondrus, \& Zmijewska, 2008). With m-payment, consumers can engage in ubiquitous online banking anytime and anywhere. Mobile payment presents noticeable advantages over the traditional online payment systems, including ubiquity, flexibility, convenience, usefulness, mobility, reachability, and compatibility (Park, Amendah, Lee, \& Hyun, 2015). According to previous studies, mobile payment services offer evident benefits to different stakeholders, especially consumers:

A. Mobile and contactless payments provide an alternative to cash. The use of these services leads to significant savings for merchants and society when compared to cash handling costs (Mallat, N., \& Tuunainen, V. K. 2005).

B. The mobile payment has a more secure payment system than traditional payment methods. Authentication is necessary to process transactions or access financial assets.

C. Mobile payments provide consumers with ubiquitous purchase possibilities and timely access to financial assets. (Mallat, N. 2007)

D. Mobile payments services can be integrated with other services, such as public transport ticketing, and provide additional value to users (Chen, J. J., \& Adams, C. 2004).

E. The ubiquity and flexibility of MPS enable consumers to purchase, transfer money, and pay bills online or at pointof-sale by quickly accessing banking accounts through their smart phones.

With the growing smartphone dependency in the United States, the mobile payment could potentially be more widely adopted with its uniqueness and advantages listed above. However, the mobile payment service is experiencing a relative slow adoption rate in the United States. 
According to the research paper "How Behavioral Science Can Unleash Digital Payments Adoption" by Simon-Kucher \& Partners, a marketing consulting firm, almost $90 \%$ of US consumers prefer to pay by cash, credit card or debit card over mobile alternatives.

China's mobile payments market was worth $\$ 17$ trillion in 2017 according to figures from iResearch quoted in the FT, roughly 35 times more than America's $\$ 49$ billion markets. Greater penetration of mobile payment services in the U.S. market would require an in-depth understanding of consumer perceptions and behavior.

The objective of this proposed study is to investigate various adoption determinants that potentially could foster the penetration of mobile payment service in the U.S. market. The study also aims to understand the reasons behind the slow adoption rate of mobile payment in the U.S. market. The awareness and understanding of the various advantages of mobile payment services might be varied among the consumers depending on their unique demographic conditions. We will also try to understand the effects of different demographic characteristics in the adoption process. Thus, our study aims to incorporate instrumentality of mobile payment, social influence, individual traits, and behavioral intention into the consideration of current adoption rate.

\subsection{Research Question}

Two major research questions for this study are:

RQ1: What are the key hindrances in the mobile payment adoption from a consumer perspective in the U.S.?

RQ2: What are the facilitators for users to use mobile payment from a consumer perspective in the U.S.?

\section{Literature Review}

In the following, we will first explain the key terminologies, and then review technology adoption models (UTAUT), and diffusion of innovation theory.

\subsection{Mobile Payments}

Mobile payment services refer to payment transactions for goods, services, and bills realized with mobile devices using wireless and other communication technologies (Dahlberg et al., 2008). Mobile payments can be broadly categorized into two categories: payments for purchases and payments of bills/invoices (Karnouskos, S., 2004). In recent years, mobile payment has been regarded by several researchers as a great potential option for consumers. In both categories, mobile payment can be an effective payment method. In payments for purchases, mobile payments could be the alternative to cash, credit cards, debit cards, and checks. It provides better convenience, flexibility, and compatibility in comparison to traditional payment methods. Also, with a more advanced authentication function, it presented to be a more secure payment method than physical cards or cash. The difference between mobile banking and mobile payment should be noted. Mobile banking typically refers to the access channel to the existing banking relationships through mobile devices. The mobile banking platforms are focused on proprietary networks operated by banks and provided to customers of the banks. (Mallet, 2007). While mobile payment generally refers to a new payment service replacing the traditional payment method in a retail market. (Mallet, 2007).

\subsection{The UTAUT model}

In general, a number of models have been developed to explain the adoption of new technologies by consumers. The technology acceptance model (TAM) is one of the most used models for studying user acceptance of technology, which identifies the perceived usefulness and perceived ease of use as the two primary factors influencing an individual's intention to use new technology.

Venkatesh et al. (2003) developed a unified theory of acceptance and use of technology model (UTAUT), which is an extension of TAM with the consideration of social influence, individual differences, and facilitating conditions. UTAUT presents to be a more validating framework in explaining technology acceptance in the past studies. The theory holds that four key constructs (performance expectancy, effort expectancy, social influence, and facilitating conditions) are direct determinants of usage intention and behavior (Venkatesh 2003). The variables of gender, age, experience, and voluntariness of use can alleviate the impact of the four key constructs on usage intention and behavior (Venkatesh et al., 2003). The UTAUT model may provide a good theoretical framework for understanding m-payment adoption, as it also includes the social and individual factors in the model itself. A number of previous studies employing the UTAUT model to investigate m-payment adoption have found the model useful. Shin (2009) extends UTAUT and suggests the social influence as a strong influence on intention. The study also identifies the security and trust are the main predictors of behavioral intention. 
Chen and Chang (2013) identifies a positive significant link between performance expectancy and social influence on attitude towards use of Near Field Communication technology extending from the UTAUT model.

\subsection{Diffusion of Innovation}

The theoretical background of this study is also derived from the Diffusion of Innovations Theory (Rogers, 1995), which have contributed to the understanding of user acceptance factors of financial and mobile technologies. The Diffusion of Innovation Theory emphasizes innovation as an agent of change in behavior with innovation identified as "a concept, practice or object perceived as new" (Rogers, 1995). Rogers also identifies the five significant qualities that determine the variation of adopting innovation, which are "relative advantage, compatibility with existing values and practices, simplicity and ease of use, trialability, and observable results" (Robinson, 2009). The theory also focuses on the importance of individual differences and peer networks to adopt innovation. According to Rogers, users are segmented into five different groups based on their propensity to adopt innovation: "innovators, early adopters, early majorities, late majorities and laggards" (Rogers, 1995). A number of past studies on information technology have applied the Diffusion of Innovation Theory into their research models and tested the validity. Yang (2012) included the two constructs, compatibility and relative advantage, into the model and validated their significant positive effect on adoption intention of mobile payment services.

\section{Conceptual Framework and Research Hypothesis}

In this research, we used the unified theory of acceptance and use of technology models (UTAUT) and the Diffusion of Innovation as the point of departure to test the extended model in the context of mobile payment. This study incorporates four constructs from UTAUT, which are perceived expectancy, effort expectancy, social influence, and facilitating conditions. The study also examines the moderating effect of the demographic characteristics of the sample on the primary constructs. Figure 1 presents the conceptual model, integrating all the key drivers of this study. In the following section, all the constructs will be defined. Their interrelationships and their relationship to behavioral intention and self-reported usage of mobile payment will be postulated.

\subsection{Conceptual Framework}

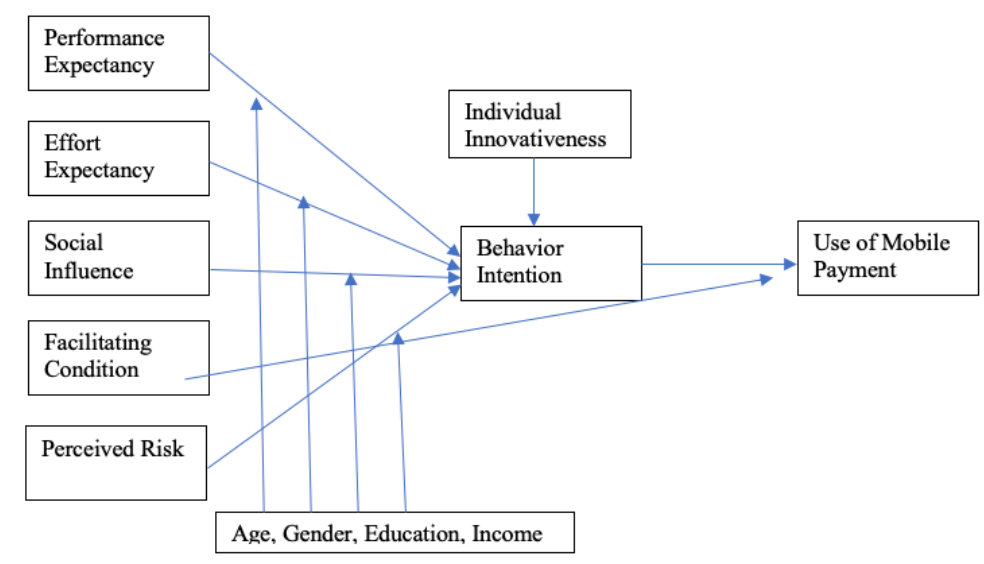

Figure 1: Conceptual Model for the Study Based on UTAUT

\subsection{Performance Expectancy}

Performance expectancy is defined as "the degree to which using a technology will provide benefits to consumers in performing certain activities" (Venkatesh, Thong \& Xu, 2012). In the past studies, researchers have found that the performance expectancy plays a significant role in determining intention to adopt. Numerous studies over the past decade have validated the significant relationship of performance expectancy and effort expectancy with the attitude of adopting technology. (Davis et al. 1989, Venkatesh 2003). Shin (2009) also verified the positive influence of performance expectancy on the attitude toward a mobile wallet. In addition, Schierz, Schilke, and Wirtz (2010) found a significant and positive relationship between the perceived usefulness and the attitude towards using mobile payment. Therefore, we proposed the following hypothesis:H1: Performance expectancy has a positive influence on the behavioral intention of adopting mobile payment.

\section{H1: Performance expectancy has a positive influence on the behavioral intention of adopting mobile payment.}




\subsection{Effort Expectancy}

Effort expectancy is defined as "the degree of ease associated with consumers' use of technology" (Venkatesh, 2012).

Many researchers have incorporated effort expectancy into the research models and verified its positive impact on the intention of adopting mobile payment. Teo et al. (1999) suggested that the information systems which are perceived to be easy to operate have a greater likelihood of being adopted. Shin (2009) also verified the positive influence of effort expectancy on the attitude toward the adoption of a mobile wallet. The results from Kim (2009) indicated that perceived ease of use exerted a significant effect on the intention to use m-payment. Thus, the following hypothesis about the effect of effort expectancy is made:

H2: Effort expectancy has a positive influence on the behavioral intention of adopting mobile payment.

\subsection{Social Influence}

Social influence is defined as "the degree to which an individual perceives that important others believe he or she should use the new system" (Venkatesh, 2003). Early researchers have found that social influence can be an important motivation for adopting new technologies. The innovation diffusion theory has considered the social influences as a critical element in explaining adoption behavior. For new technology innovations involving connectivity among peers, people tend to adopt more peer-to-peer communication, and social influence is thus expected to be an important factor for the adoption of technology with network externalities (Dickinger, Arami, \& Meyer, 2008). Hong and Tam (2006) concluded that social influences affect adoption intention directly and indirectly via perceived usefulness in their study. Lee, Murphy, and Swilley (2009) showed that social influence can affect individuals' behaviors in adoption of mobile phone services. Yang (2012) suggested that the social influences (subjective norm and image), and personal traits are found to have significant direct influence on adoption intention of mobile payment services. On the other hand, social influences provide the legitimacy and appropriateness of the adoption decision, thus the perceived risk of adoption tends to be reduced. (Karahanna et al., 1999). By the reference of previous literatures, we thus hypothesize that:

H3: Social influence has a positive influence on the behavioral intention of adopting mobile payment.

\subsection{Facilitating Condition}

Facilitating condition is defined as "the degree to which an individual believes that an organizational and technical infrastructure exists to support use of the system" (Venkatesh, 2003). In this study of mobile payment adoption, facilitating condition refers to "whether an individual believes that some enabling factors exist to support acceptance of the system' (Miltgen, 2013). Past studies indicate that the support services and resources would encourage customers to use mobile banking. Miltgen (2013) and Alalwan (2017) both confirms the positive influence of facilitating conditions on behavioral intention. Thus, the study hypothesizes that the greater facilitating condition will increase the likelihood of self-reported usage of mobile payment.

H4: Facilitating condition has a positive influence on the self-reported usage of mobile payment.

\subsection{Perceived Risk}

Perceived risk is defined as "as the subjective information that consumers feel they will bear loss when purchasing certain products" (Yang, 2014) Perceived risk, privacy concerns and trust have been overlooked by the UTAUT model. However, many researches suggested perceived risk as an important factor for evaluation of the adoption of online payment in general. Researchers have explored the relationship between perceived risks and consumers' intention of adopting technology. Yang, Qian, and Pang (2014) have categorized consumer perceived risks in online payment into economic, security, private, and time, etc. They concluded that the higher the risk consumers perceived, the less willing they were to use online payment. In the study by Park, Amendah, Lee, and Hyun (2015), they also verified perceived risks have conspicuous negative correlations with online payment willingness. According to Mondego (2018), institutional-based trust shows a positive impact on post-adoption perceived usefulness and a negative impact on postadoption perceived risk. Amin's study of the adoption of mobile phone credit cards (2008) indicates consumers demand a completely safe program.

\section{H5: Perceived risk of mobile payment services negatively affects the intention to adopt mobile payment.}

\subsection{Individual Innovativeness}

Agarwal and Prasad (1998) defined personal innovativeness in information technology (PIT) as the degree of willingness of an individual to try out new information technology. 
Past researchers suggested that individual innovativeness positively influences the individual's perception toward the relative advantage, ease of use, compatibility and intention of the new technology (Agarwal and Prasad 1998, Lu et al. 2008, Yang 2012). Lewis et al. (2003) validated that personal innovativeness has a strong effect on the perceived usefulness of the new technology. Lu et al. (2008) found a positive effect of PIIT on the intention of adopting wireless mobile data services.

The study by Yang (2012) showed the positive effect of PIIT on behavioral intention and relative benefit were both significant. According to the review of previous studies, we expect that the individual innovativeness should have a positive impact on the behavioral intention to adopt m-payment. Thus, the current study proposes that:

H6: Individual Innovativeness has a positive influence on the behavioral intention of the mobile payment.

\subsection{Behavioral Intention and Self-reported Usage of the Mobile Payment}

Intention to use technology is a major component of the TAM model (Davis, 1989) and the UTAUT model(Venkatesh, 2003). The UTAUT model suggests that a person's behavioral intention of performing a specified behavior is a significant driving factor on the self-reported performance.

H7: Behavioral intention of adopting the mobile payment has a significant positive influence on the self-reportedusage of the mobile payment.

\section{Methodology}

\subsection{Participants}

The participant screening criteria is over 18 years old and owns a smartphone. An online survey was conducted through Survey Monkey in April 2020. A total of 233 responses were collected, and 214 complete responses were used for the data analysis.

\subsection{Survey Design}

Table 1 lists our survey construct, corresponding survey questions, and sources.

Table 1: Survey Construct, Questions and Sources for the Study

\begin{tabular}{|c|c|c|}
\hline Construct & Source & Survey Questions \\
\hline $\begin{array}{l}\text { Performance } \\
\text { Expectancy }\end{array}$ & $\begin{array}{l}\text { Schierz (2009) } \\
\text { Park (2015) } \\
\text { Venkatesh (2003) }\end{array}$ & $\begin{array}{l}\text { Q1: As a consumer, I think mobile payment services ... } \\
\text { provide me more choices when I make a payment. } \\
\text { offer me a wider range of financial products, services, and } \\
\text { investment opportunities. } \\
\text { is useful in my purchase process. } \\
\text { enables me to accomplish payment more quickly. }\end{array}$ \\
\hline Effort Expectancy & $\begin{array}{l}\text { Park (2015) } \\
\text { Morgan (2015) } \\
\text { Venkatesh (2003) }\end{array}$ & $\begin{array}{l}\text { Q2: As a consumer, I feel ... } \\
\text { easy to learn mobile payment app. } \\
\text { easy to use mobile payment app. } \\
\text { easy to get mobile payment app to do what I want it to do. } \\
\text { My interaction with mobile payment procedure is clear and } \\
\text { understandable. } \\
\text { My interaction with mobile payment apps is flexible. }\end{array}$ \\
\hline Social Influence & $\begin{array}{l}\text { Morgan (2015) } \\
\text { Venkatesh (2003) }\end{array}$ & $\begin{array}{l}\text { Q3: Social influence } \\
\text { People who influence my behavior would think that I should } \\
\text { use the mobile payment app. } \\
\text { People who are important to me would suggest that I use a } \\
\text { mobile payment app. } \\
\text { People in my close circle who use the mobile payment app } \\
\text { have more prestige than those who do not. } \\
\text { I use mobile payment apps, because some of my friends use }\end{array}$ \\
\hline
\end{tabular}




\begin{tabular}{|c|c|c|}
\hline & & them. \\
\hline $\begin{array}{l}\text { Facilitating } \\
\text { Condition }\end{array}$ & Venkatesh (2003) & $\begin{array}{l}\text { Q4: Facilitating Condition } \\
\text { I have the resources necessary to use a mobile payment app. } \\
\text { I have the knowledge necessary to use a mobile payment app. } \\
\text { I think mobile payment apps are compatible with other apps I } \\
\text { use. }\end{array}$ \\
\hline Perceived Risk & $\begin{array}{l}\text { Schierz (2009) } \\
\text { Park (2015) } \\
\text { Yang (2001) }\end{array}$ & $\begin{array}{l}\text { Q5: When using mobile payment ... } \\
\text { I feel risk of abuse of usage of information is low. } \\
\text { I perceive mobile payment services as a safe payment } \\
\text { transaction. } \\
\text { I worry that other people might be able to access my account. } \\
\text { I would not feel totally safe providing personal information } \\
\text { over mobile payment apps. }\end{array}$ \\
\hline $\begin{array}{l}\text { Individual } \\
\text { Innovativeness }\end{array}$ & $\begin{array}{l}\text { Kim (2009) } \\
\text { Yang (2011) }\end{array}$ & $\begin{array}{l}\text { Q6: Innovativeness } \\
\text { I know more about new technology before other people do. } \\
\text { I am usually among the first to explore new information } \\
\text { technology. } \\
\text { New products excite me. } \\
\text { If I heard about a new information technology, I would look for } \\
\text { ways to experiment with it. }\end{array}$ \\
\hline $\begin{array}{l}\text { Behavioral } \\
\text { Intention }\end{array}$ & $\begin{array}{l}\text { Morgan (2015) } \\
\text { Venkatesh (2003) } \\
\text { Yang (2011) }\end{array}$ & $\begin{array}{l}\text { Q7: In the near future... } \\
\text { I intend to use mobile payment app } \\
\text { I predict that I will use mobile payment app } \\
\text { I plan to use mobile payment app }\end{array}$ \\
\hline $\begin{array}{l}\text { Self-reported } \\
\text { Usage of Mobile } \\
\text { Payment }\end{array}$ & Morgan (2015) & $\begin{array}{l}\text { Q8: Self-reported Usage } \\
\text { How often do you use mobile payments? } \\
\text { Where do you usually use mobile payment? } \\
\text { What products do you usually use mobile payment to pay for? } \\
\text { How much money will you be willing to pay with mobile } \\
\text { payment services? }\end{array}$ \\
\hline
\end{tabular}

\section{Results \& Discussion}

\subsection{Analysis of Demographic Results}

A sample size of 214 was collected through an online survey. Table 2 presents the demographic statistic for the sample. The sample is representative of the US market in terms of age, gender, income, and ethnicity. The participants of all generations (above 18) are included in the study. The gender ratio of the sample is almost one to one with 114 females $(53.02 \%)$ and 100 males $(46.51 \%)$. The sample consists of a large percentage of white Americans (72.90\%), which is consistent with the fact of white majority in the U.S market. The statistic shows the percentage distribution of household income is approximately uniform. The education level of the sample is not equally distributed, which might result in a slight bias in their responses. 
Table 2: Sample Demographics $($ Total =214)

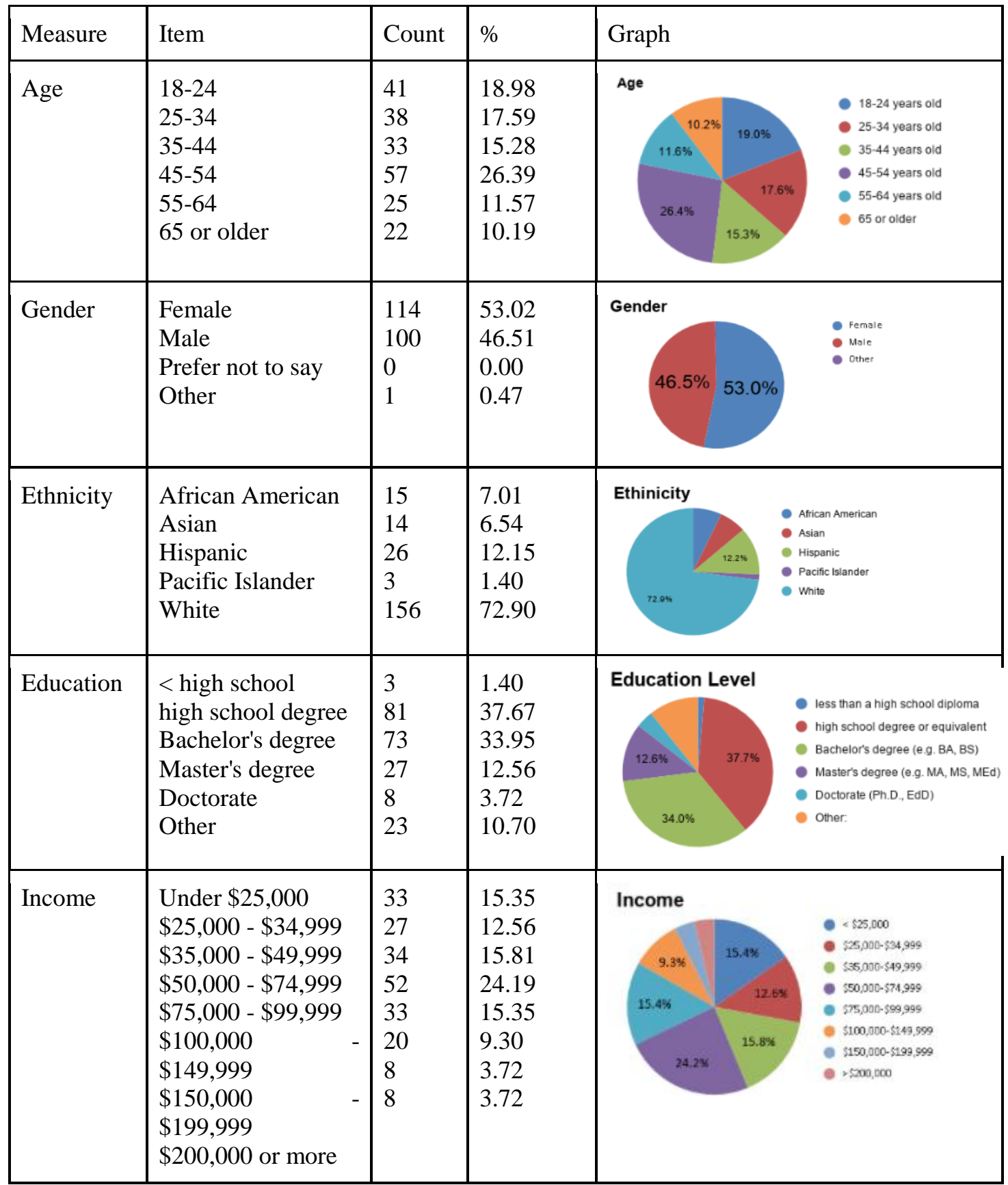

\subsection{Results of Descriptive Analysis}

Figure 2-5 shows the average rating of 4 constructs from the UTATU model: performance expectancy, effort expectancy, social influence, and facilitating condition. They are all above 3 on a 5-likert scale.

For performance expectancy, the majority of the sample agreed that mobile payment is useful in providing them a better purchase process. For effort expectancy, the majority of our participants reported the mobile payment easy to use and easy to learn. For social influence, the sample leans towards neutral on the impact of social influence on adopting mobile payment. For the facilitating condition, the sample also has positive perception on the facilitating condition. 
As a consumer, I think that mobile payment services...

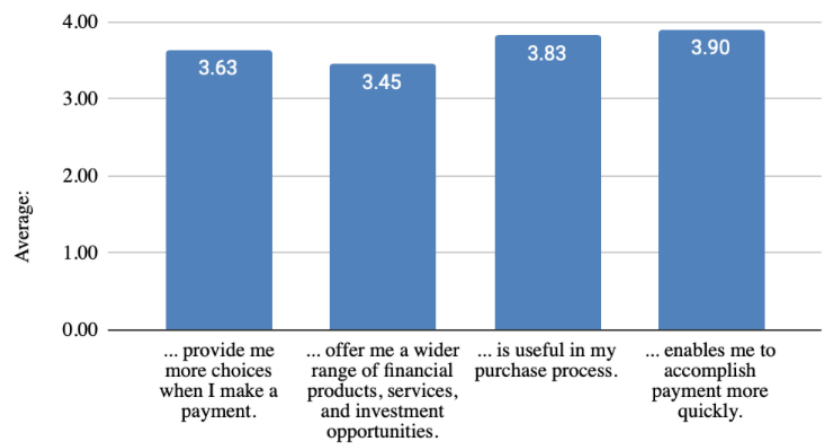

Figure 2: Performance Expectancy

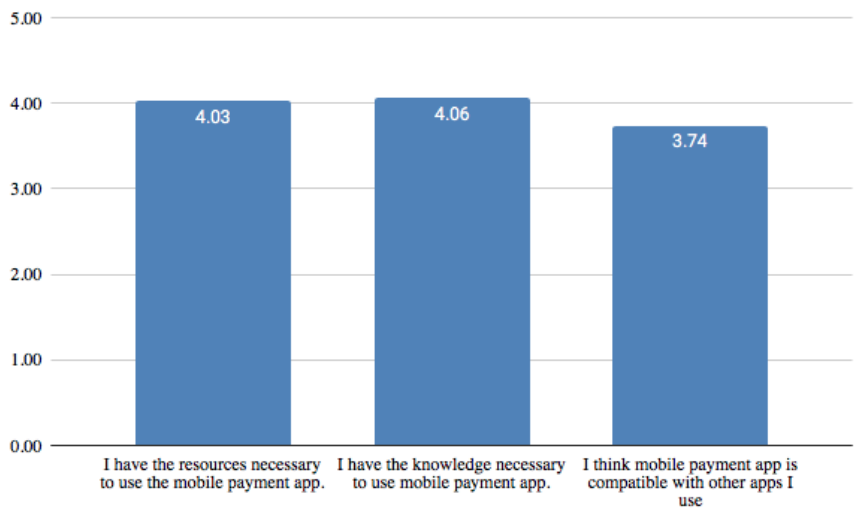

As a consumer, I feel...

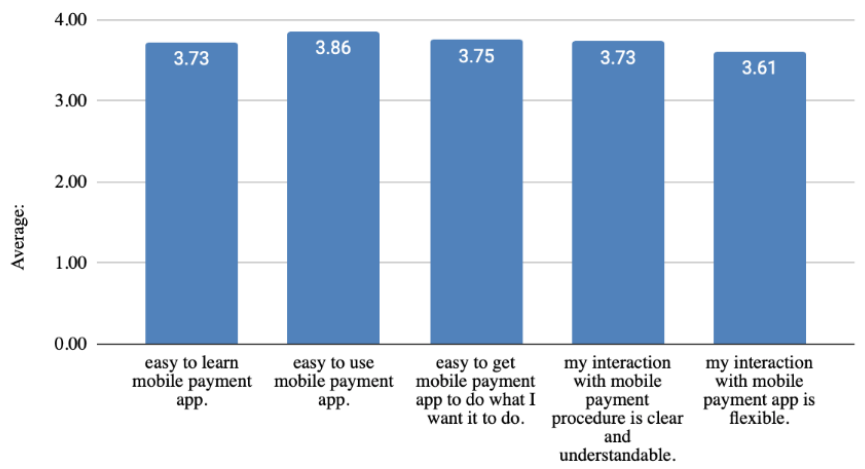

Figure 3: Effort Expectancy

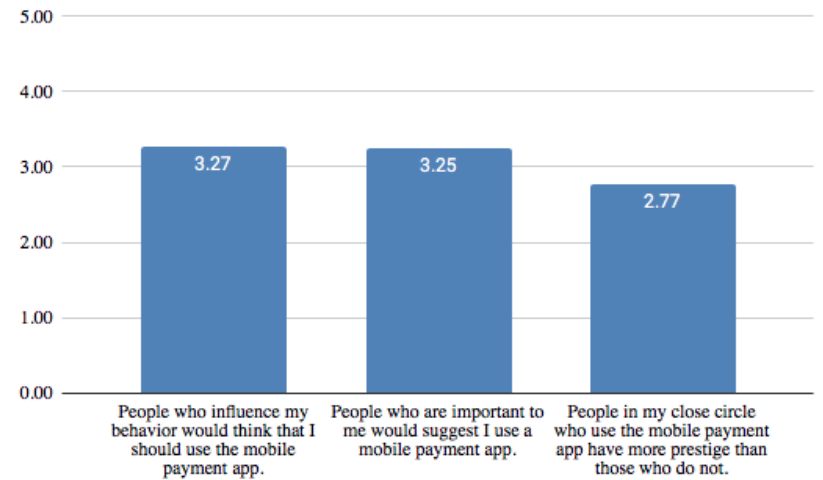

Figure 4: Social Influence 


\section{Figure 5: Facilitating Condition}

The four items of perceived risk show a conflicted result (Figure 6). After the reliability test, the first two items are removed from this study. Thus, the sample generally presents a concern over the security issue when using mobile payment.

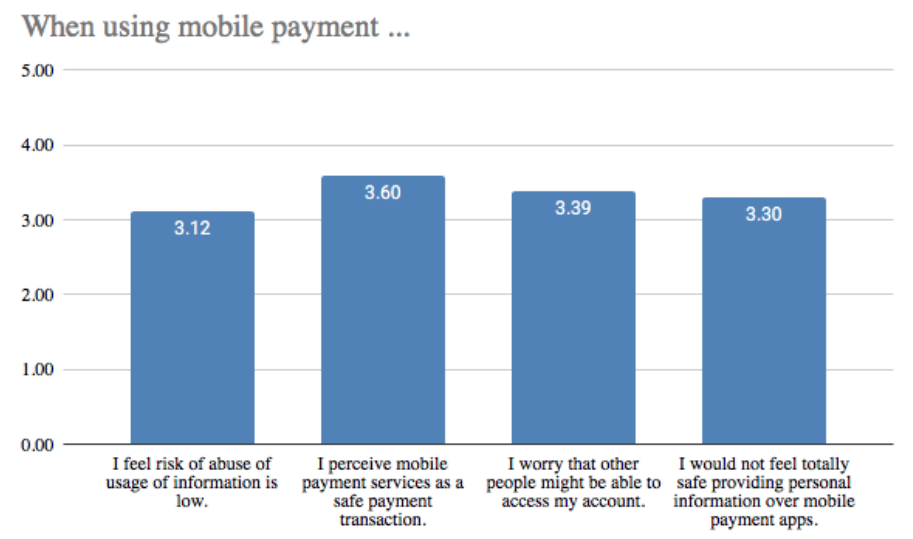

\section{Figure 6: Perceived Risk}

Figure 7 show that the average of four items of individual innovativeness are all above 3.0 on a 5-likert scale, indicating that the sample has relatively high individual innovativeness.

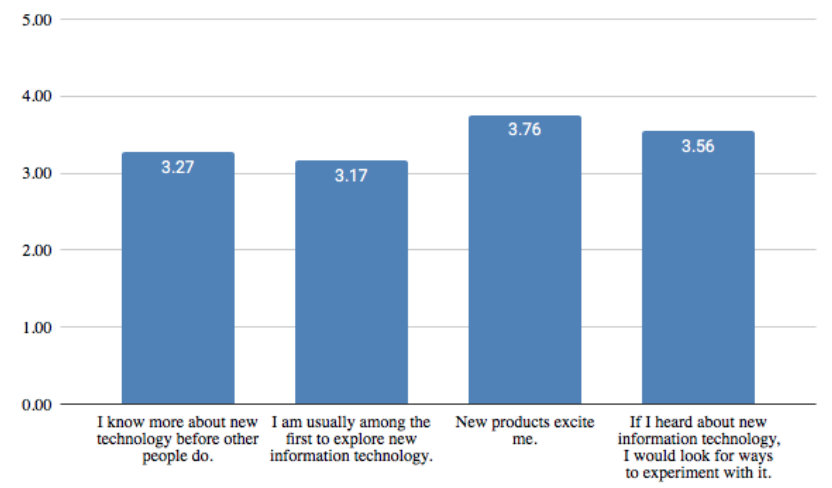

Figure 7: Innovation

As shown in Figure 8, the behavioral intention of the sample is relatively high with all the average above 3.7 on a 5 likert scale.

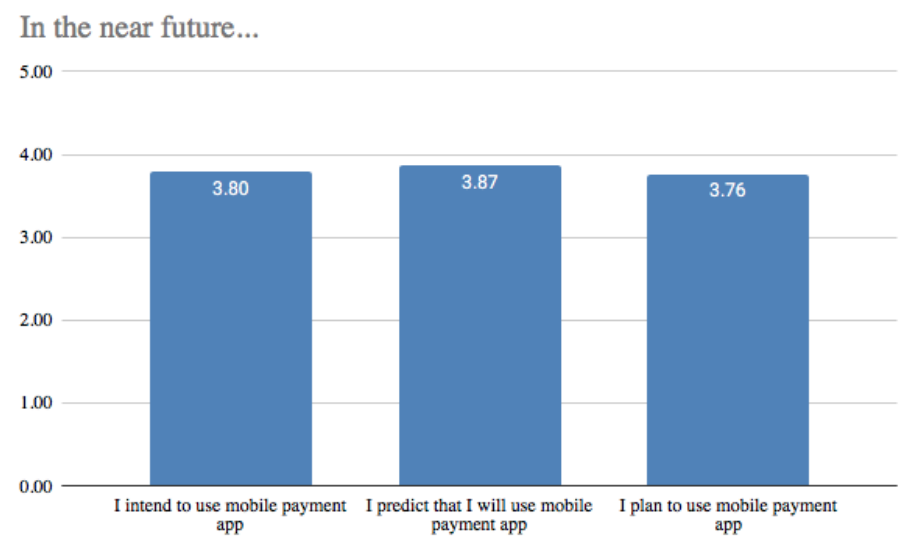

Figure 8: Behavioral Intention 


\subsection{Results of Path Analysis}

Structural equation modeling was used to assess the relationships described in the model. In addition, ANOVA and ttest analysis of variance were conducted to assess the moderating effects of various demographic factors on behavior intention.

Analysis of Structural Equation Modeling was conducted in SPSS-AMOS.

Table 3: Reliability and Validity Testing Results

\begin{tabular}{lcccl}
\hline \multicolumn{2}{c}{ Construct $\alpha$} & $>.5$ & $>.65$ & $\begin{array}{l}\text { Convergent } \\
\text { Validity }\end{array}$ \\
\hline PE & 0.86 & 0.59 & 0.85 & Established \\
EE & 0.91 & 0.67 & 0.91 & Established \\
SI & 0.79 & 0.58 & 0.81 & Established \\
FC & 0.78 & 0.55 & 0.78 & Established \\
Risk & 0.66 & 0.50 & 0.67 & Established \\
Innov & 0.86 & 0.61 & 0.86 & Established \\
\hline
\end{tabular}

PE: performance expectancy; EE: effort expectancy; SI: social influence; FC: facilitating condition; Risk=perceived risk; Innov=Innovation

As shown in Table 3, each construct of the survey was tested for reliability by calculating Cronbach's alpha. Alpha scores of above 0.6 are considered acceptable scores to demonstrate the internal consistency between factor items (Nunnally, 1988). The Cronbach's alpha for all the constructs in our study were above the acceptance level. The average variance extracted (AVE) for every construct was above 0.5 , indicating acceptable convergent validities for all constructs. The composite reliabilities (CR) were greater than 0.7 . All the items passed the reliability and validity test. As a result, the data were found to be appropriate for further analysis.

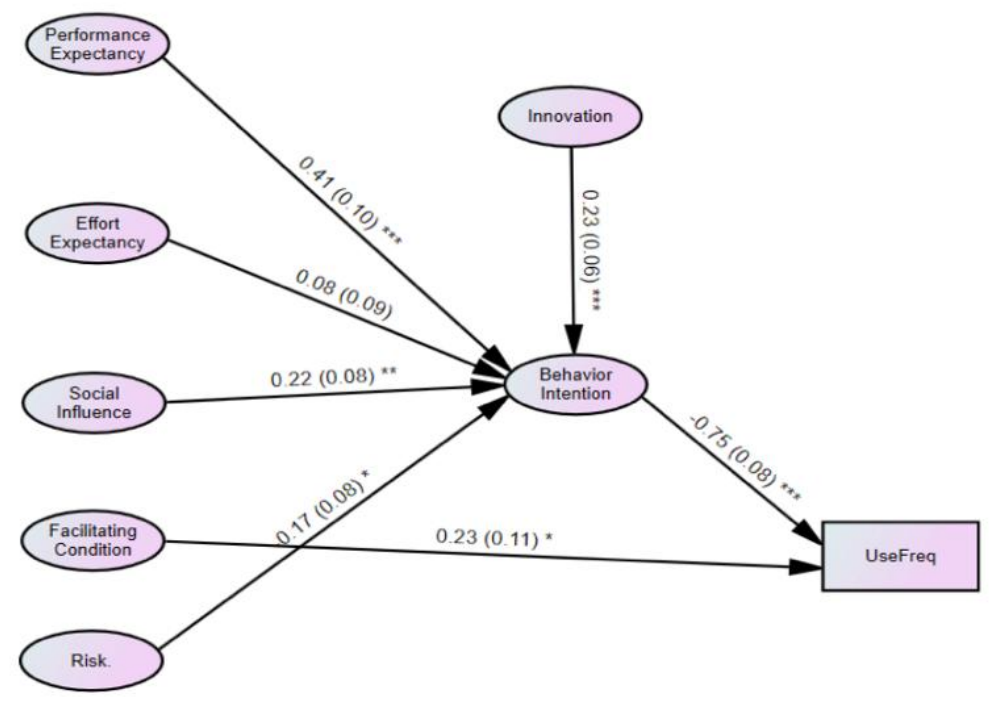

Figure 9: Results of Proposed Model

The measurement model showed good fits to the data. The self-reported values of the model fit indices are: Chi-square $(255)=532.90, \mathrm{p}<0.00 ; \mathrm{GFI}=0.83 ; \mathrm{AGFI}=0.78 ; \mathrm{CFI}=0.91 ; \mathrm{RESEA}=.07$. The self-reported values of the fit indices are better than the recommended values. Thus, the overall fit of the model and data were satisfied. 
Table 4: Testing Results of Conceptual Model

\begin{tabular}{|c|c|c|c|c|}
\hline \multirow{2}{*}{$\begin{array}{l}\text { Paths } \\
\text { (Hypothesis) }\end{array}$} & \multicolumn{2}{|c|}{ Direct Effect } & \multicolumn{2}{|c|}{$\begin{array}{l}\text { Mediating } \\
\text { Effect }\end{array}$} \\
\hline & $\begin{array}{l}\text { Estimate } \\
\text { ( } \mathrm{p} \text { value) }\end{array}$ & $\begin{array}{l}\text { Suppo } \\
\mathrm{rt}\end{array}$ & $\begin{array}{l}\text { Estimate } \\
(p \text { value })\end{array}$ & $\begin{array}{l}\text { Sup } \\
\text { port }\end{array}$ \\
\hline $\mathrm{PE} \rightarrow \mathrm{BI}: \mathrm{H} 1$ & $\begin{array}{l}0.41 \\
(0.10) \\
* * *\end{array}$ & Yes & & \\
\hline $\mathrm{EE} \rightarrow \mathrm{BI}: \mathrm{H} 2$ & $\begin{array}{l}0.08 \\
(0.09)\end{array}$ & No & & \\
\hline $\mathrm{SI} \rightarrow \mathrm{BI}: \mathrm{H} 3$ & $\begin{array}{l}0.22 \\
(0.08) * *\end{array}$ & Yes & & \\
\hline Risk $\rightarrow$ BI: H5 & $\begin{array}{l}-0.17 \\
(0.08)^{*}\end{array}$ & Yes & & \\
\hline Innov $\rightarrow$ BI: H6 & $\begin{array}{l}0.23 \\
(0.06)^{* *} \\
*\end{array}$ & Yes & & \\
\hline $\mathrm{FC} \rightarrow$ Use: $\mathrm{H} 4$ & $\begin{array}{l}0.23 \\
(0.1) *\end{array}$ & Yes & & \\
\hline BI $\rightarrow$ Use: H7 & $\begin{array}{l}-0.75 \\
(0.08) *\end{array}$ & No & & \\
\hline $\begin{array}{l}\mathrm{PE} \\
\text { Use }\end{array}$ & & & $\begin{array}{l}-0.31 \\
(0.08) \\
* * *\end{array}$ & Yes \\
\hline $\begin{array}{l}\mathrm{EE} \rightarrow \mathrm{BI} \rightarrow \\
\text { Use }\end{array}$ & & & $\begin{array}{l}-0.06 \\
(0.07)\end{array}$ & No \\
\hline $\mathrm{SI} \rightarrow \mathrm{BI} \rightarrow$ Use & & & $\begin{array}{l}-0.17 \\
(0.06) * *\end{array}$ & Yes \\
\hline $\begin{array}{l}\text { Risk } \rightarrow \text { BI } \rightarrow \\
\text { Use }\end{array}$ & & & $\begin{array}{l}0.13 \\
(0.06)\end{array}$ & No \\
\hline $\begin{array}{l}\text { Inno } \rightarrow \text { BI } \rightarrow \\
\text { Use }\end{array}$ & & & $\begin{array}{l}-0.17 \\
(0.05) \\
* * *\end{array}$ & Yes \\
\hline
\end{tabular}

As shown in Figure 9 and Table 4, all hypotheses except $\mathrm{H} 2$ and $\mathrm{H} 7$ were supported. H1 was supported, as we found a significant and positive relationship between the performance expectancy and the behavioral intention of adopting mobile payment. The result also supported that social influence had a positive influence on behavioral intention of adopting mobile payment (H3). Moreover, a significant and positive relationship was supported between the facilitating condition and the frequency of use (H4). The negative effect of perceived risk on the behavioral intention (H5) was supported. Finally, the positive influence of individual innovativeness on the behavioral influence (H6) is supported.

However, the positive effect of effort expectancy on the behavioral intention of adopting mobile payment (H2) was rejected. One plausible explanation is that the ceiling effect might exist for users' perception of easiness for using mobile payment. The ease of use might not be current users' primary consideration of adopting mobile payment, as they might be easier to accept the difficulty of adopting new technology. Meanwhile, the positive influence of behavioral intention on the self-reported usage of mobile payment $(\mathrm{H} 7)$ was also rejected. One plausible reason for this result is that we had limitations in measuring the self-reported usage of users. The one-time survey for our sample might not be able to provide an effective measurement of their self-reported usage without follow-up observations. Thus, we only used the frequency of use as the simple report for the self-reported usage.

The behavioral intention is examined as a mediating factor in the relation between six key constructs and the selfreported usage. In Table 4, the mediating effect of behavioral intention is significant for performance expectancy, social influence, and innovativeness to self-reported use.

As a compensation of this limitation, we used an open-ended question to better understand the self-reported use of mobile payment of current users. 
Table 5: Testing Results of Moderating Effect: Coefficient (SE)

\begin{tabular}{|c|c|c|c|c|c|}
\hline & & $\begin{array}{l}\text { Sample } \\
\text { Size }\end{array}$ & $\mathrm{PE} \rightarrow \mathrm{BI}$ & $\mathrm{SI} \rightarrow \mathrm{BI}$ & Risk $\rightarrow$ BI \\
\hline \multicolumn{2}{|l|}{ Total } & & $\begin{array}{l}0.41 \\
(0.095) * * *\end{array}$ & $\begin{array}{l}0.22 \\
(0.078) * *\end{array}$ & $\begin{array}{l}-0.17 \\
(0.078) *\end{array}$ \\
\hline \multirow[t]{3}{*}{ Gender } & Male & 92 & $0.54(.12)$ & $0.11(.13)$ & $-0.07(.15)$ \\
\hline & Female & 109 & $0.37(.08)$ & $0.27(.07)$ & $-0.23(.09)$ \\
\hline & & $t(197)$ & $\begin{array}{c}1.17 \\
(p=.24)\end{array}$ & $1.03(p=.31)$ & $0.96(p=.34)$ \\
\hline \multirow[t]{8}{*}{ Age } & $18-24$ & 39 & $0.42(.35)$ & $-0.50(.46)$ & $-0.07(.29)$ \\
\hline & $25-34$ & 37 & $0.37(-.07)$ & $-0.01(.23)$ & $-0.21(.13)$ \\
\hline & $35-44$ & 30 & $-0.07(.14)$ & $0.13(.09)$ & $-0.29(.13)$ \\
\hline & $45-54$ & 53 & $0.51(.16)$ & $0.36(.13)$ & $-0.40(.13)$ \\
\hline & $55-64$ & 24 & $0.79(.23)$ & $0.23(.14)$ & $0.08(.11)$ \\
\hline & 65 and older & 20 & $0.77(.15)$ & $0.28(.12)$ & $0.24(1.32)$ \\
\hline & & $F(5,197)$ & 45.27 & 67.71 & 8.60 \\
\hline & & $p$ & $* * *$ & $* * *$ & $* * *$ \\
\hline \multirow{6}{*}{$\begin{array}{l}\text { Educatio } \\
\mathrm{n}\end{array}$} & High School & 79 & $0.38(.13)$ & $-0.33(.15)$ & $-0.15(.12)$ \\
\hline & Bachelor & 71 & $0.36(.09)$ & $0.42(.09)$ & $-0.12(.14)$ \\
\hline & Graduate & 33 & $0.20(.10)$ & $0.04(.09)$ & $-0.21(.11)$ \\
\hline & Other & 20 & $0.17(.18)$ & $0.69(.17)$ & $-0.13(.18)$ \\
\hline & & $F(3,199)$ & 31.67 & 594.37 & 3.37 \\
\hline & & $p$ & $* * *$ & $* * *$ & 0.02 \\
\hline \multirow[t]{8}{*}{ Income } & under $\$ 25,000$ & 29 & $0.39(.13)$ & $0.09(.15)$ & $0.20(.19)$ \\
\hline & $\$ 25,000-34,999$ & 26 & $0.56(.15)$ & $0.13(.19)$ & $0.50(.19)$ \\
\hline & $\$ 35,000-49,999$ & 31 & $0.46(.15)$ & $0.41(.22)$ & $0.03(.20)$ \\
\hline & $\$ 50,000-74,999$ & 49 & $0.22(.09)$ & $0.20(.07)$ & $-0.12(.11)$ \\
\hline & $\$ 75,000-99,999$ & 32 & $0.74(.07)$ & $-0.08(.06)$ & $0.08(.08)$ \\
\hline & $\$ 100,000-149,999$ & 20 & $0.68(.17)$ & $0.15(.17)$ & $-0.06(.19)$ \\
\hline & & $\mathrm{F}(5,181)$ & 88.81 & 36.46 & 44.05 \\
\hline & & $p$ & $* * *$ & $* * *$ & $* * *$ \\
\hline
\end{tabular}

Note: Given $\mathrm{H} 2(\mathrm{EE} \rightarrow \mathrm{BI})$ was rejected in our model, the moderating effects of demographic factors (gender, age, education, and income) on this relationship were skipped.

As shown in Table 5, although the moderating effect of gender was not significant $(p>.05)$ for all three pairs (PE $\rightarrow \mathrm{BI}$ , SI $\rightarrow \mathrm{BI}$, Risk $\rightarrow \mathrm{BI}$ ), the moderating effects of the rest of demographic factors (Age, Education, Income) were ALL significant for all three pairs $(\mathrm{PE} \rightarrow \mathrm{BI}, \mathrm{SI} \rightarrow \mathrm{BI}$, Risk $\rightarrow \mathrm{BI}$ ).

The Post-hoc pairing t-test showed that Age group of 35-44 were significantly lower than Age 45-54, 55-64, and 65 or older for $\mathrm{PE} \rightarrow \mathrm{BI}$; Age group of 55-64 were significantly higher than Age group 25-34 and 35-44 for Risk $\rightarrow$ BI (all $p<.05)$.

The Post-hoc t-test for education moderating effect revealed that the Graduate group was significantly different from Undergraduate and High School groups for SI $\rightarrow$ BI (all $p<.05$ ). While people with undergraduate degrees were more socially influenced for mobile payment intentions than people with graduate degrees, people with high school diplomas were less socially influenced for mobile payment intentions than people with graduate degrees.

The Post-hoc t-test for income moderating effects demonstrated interesting results for the relationship of PE $\rightarrow$ BI. The middle income groups $\$ 50 \mathrm{k}-75 \mathrm{k}$ and $\$ 75 \mathrm{k}-100 \mathrm{k}$ were significantly lower than lower income groups $\$ 25 \mathrm{k}-50 \mathrm{k}$ and under $\$ 25 \mathrm{k}$ respectively. The middle income groups $\$ 50 \mathrm{k}-75 \mathrm{k}$ was also significantly lower than the high income group $\$ 100 \mathrm{k}-150 \mathrm{k}$. For the moderating effect of income on $\mathrm{SI} \rightarrow \mathrm{BI}$, the income group of $\$ 75 \mathrm{k}-100 \mathrm{k}$ was significantly lower than groups of $\$ 35 \mathrm{k}-50 \mathrm{k}$ and $\$ 50 \mathrm{k}-75 \mathrm{k}$. It appears that when people have more income, the social influence effect on behavior intention to mobile payment will be reduced. Finally, the income group of $\$ 25 \mathrm{k}-50 \mathrm{k}$ was higher than groups of $\$ 50 \mathrm{k}-75 \mathrm{k}, 75 \mathrm{k}-100 \mathrm{k}$, and $100 \mathrm{k}-150 \mathrm{k}$ for moderating effect of income on Risk->BI. 


\section{Conclusion}

The main objective of this study is to investigate the major hindrances and facilitators in mobile payment adoption of current consumers. We attempted to understand the reasons behind the relative slow penetration of mobile payment in the United States market. For this objective, a proposed model is established with six constructs with the extension of UTAUT model and Diffusion of Innovation Theory. We also examined the role of demographics conditions as moderating factors in the proposed model.

The findings of this study have potential contributions to the future development of mobile payment in the United States market. The major contributions of the study are as follows. First, the study successfully extended the UTAUT model with the incorporation of perceived risk and individual innovativeness. Our finding shows that employing perceived risk and individual innovativeness is an effective extension from the UTAUT model. We confirmed the validity of the positive influence of perceived expectancy, social influence, and facilitating conditions toward the intention of adopting mobile payment from the UTAUT model. The result also shows the positive influence of individual innovativeness towards behavioral intention, which has been overlooked in the UTAUT model. We also found the negative influence of perceived risk towards the intention of adopting mobile payment. The perceived risk of using mobile payment still remains as a major hindrance for the extensive uptake of the mobile in the United States market. For a greater adoption rate of mobile payment, the security issue should be improved to diminish the extent of perceived risk from the consumer side. Second, we found the insignificant effect of effort expectancy toward the intention of mobile payment adoption, which is a new finding from the previous studies. The plausible explanation for this result is that the easiness of adopting new information technology is no longer a primary concern of the current users. With the context of the high technology penetration rate in U.S. society, the insignificance of technology adoption difficulty that current users perceive is reasonable. This finding is valuable for future researchers in further developing the research model. Third, the result shows that the moderating effect of age, income, and education are all significant. However, the gender is an insignificant moderating effect. Finally, we examined the self-reported use of mobile payment with open-ended questions. We found that the majority of our sample (78.95\%) indicated that their use of mobile payment remains online. The result demonstrates a low penetration of in-store mobile payment transactions, while more users are accepting mobile payment for online purchase. This important finding contributes to the future direction for a greater expansion of mobile payment adoption.

\section{Limitations and Future Studies}

The study contributes several important implications for future researchers as well as for the mobile payment industry. The concept model of this study can provide a better understanding of the consumer perspective on the adoption of mobile payment. Practical application and strategies of the industry can be drawn from this study. The security issue remains as a hindrance from a greater adoption rate of the mobile payment. The improvement over transaction safety and the elimination of users' perceived risk would foster the adoption of mobile payment in the United States market. The industry service provider and researchers need to develop a better understanding and solution on the individual concerns of transaction security. As more users are accepting mobile payment as a new means for online transactions, the factors behind low in-store adoption of mobile payment needs further investigation.

Our study primarily focuses on the several factors for the intention of mobile payment adoption. Thus, this study has limitations on the long-term measurement of users' self-reported usage of mobile payment. We used a one-time survey as the methodology of this study, which does not enable us to have a better understanding on the self-reported usage of mobile payment from the consumer side. In future studies, the interview or focus group can be used to understand the long-term self-reported use of the mobile payment from current user experiences.

From our study, the current users show a general readiness for the adoption of mobile payment. For greater diffusion of the mobile payment in the U.S. market, more perspectives from different stakeholders need to be studied. The challenges from service providers and merchants should be examined to better understand the slow uptake of in-store mobile payment adoption. After the challenges are understood and overcome, we believe that mobile payment would become a major means of application for the next generation in the United States.

\section{Reference}

Chen, J. J., \& Adams, C. (2004). Short-range wireless technologies with mobile payment systems. Paper presented at the 6th International Conference on e-commerce, Delft University of Technology, The Netherlands, 25-27 October. 
Chen, K.-Y., \& Chang, M.-L. (2013). User acceptance of 'near field communication' mobile phone service: an investigation based on the 'unified theory of acceptance and use of technology' model. The Service Industries Journal, 33(6), 609-623. doi: 10.1080/02642069.2011.622369

Dahlberg, Tomi; Mallat, Niina; Ondrus, Jan; and Zmijewska, Agnieszka. (2008). " Mobile Payment Market and Research - Past, Present and Future".All Sprouts Content. 166.

Dennehy, D., \&Sammon, D. (2015). Trends in mobile payments research: A literature review. Journal of Innovation Management, 3(1), 49-61.

Karnouskos, Stamatis. "Mobile payment: A journey through existing procedures and standardization initiatives." IEEE Communications Surveys \& Tutorials 6.4 (2004): 44-66.

Ke, W., Chung, D., Li, W., \& Furgiuele, J. (2019) How Behavioral Science Can Unleash Digital Payments Adoption" by Simon-Kucher \& Partners. Retrieve on 10/25/2019:https://www.simon-kucher.com/sites/default/files/201901/SimonKucher_Report_Payment\%20Adoption_Final.pdf

Kim, C., Mirusmonov, M., \& Lee, I. (2010). An empirical examination of factors influencing the intention to use mobile payment. Computers in Human Behavior, 26(3), 310-322.

Koenig-Lewis, N.; Morgan, M., Palmer, A. and Zhao, A. (2015). Enjoyment and social influence: predicting mobile payment adoption. The Service Industries Journal 35(10), pp. 537-554. (10.1080/02642069.2015.1043278)

Koenig-Lewis, Nicole, Marquet, Morgan, Palmer, Adrian and Zhao, Anita Lifen 2015. Enjoyment and social influence: predicting mobile payment adoption. The Service Industries Journal 35 (10) , pp. 537-554. 10.1080/02642069.2015.1043278 file

Mallat, N. (2007). Exploring consumer adoption of mobile payments-A qualitative study. The Journal of Strategic Information Systems, 16(4), 413-432.

Mondego, D. (2018) Understanding the influence of trust on mobile payment systems adoption: A literature review International Journal of Research in IT and Management, Vol. 8, Issue 5.

Park J, Amendah E, Lee Y, Hyun H. (2015). M-payment service: Interplay of perceived risk, benefit, and trust in service adoption. Hum Factors Man. 2019;29:31-43

Riquelme, I. P., \& Román, S. (2014). Is the influence of privacy and security on online trust the same for all type of consumers?.Electronic Markets, 24(2), 135-149.

Schierz, P. G., Schilke, O., \& Wirtz, B. W. (2010). Understanding consumer acceptance of mobile payment services: An empirical analysis. Electronic commerce research and applications, 9(3), 209-216.

Shin, D.-H. (2009). Towards an understanding of the consumer acceptance of mobile wallet. Computer in Human Behavior, 25(6), 1343-1354. doi: 10.1016/j.chb.2009.06.001

Stavins, J. (2016). The effect of demographics on payment behavior: panel data with sample selection.

Venkatesh, V., Morris, M., Davis, G., \& Davis, F. (2003). User Acceptance of Information Technology: Toward a Unified View. MIS Quarterly,27(3), 425-478. doi:10.2307/30036540

Yang, Q., Qian, X., Pang, C., \& An, B. (2014, June). Empirical Study on Consumer Perceived On-line Payment Risk. In WHICEB (p. 58).

Yang, S., Lu, Y., Gupta, S., Cao, Y., \& Zhang, R. (2012). Mobile payment services adoption across time: An empirical study of the effects of behavioral beliefs, social influences, and personal traits. Computers in Human Behavior, 28(1), 129-142. 